\title{
MUDANÇA DE PARADIGMAS: DESAFIO PARA O PROFESSOR DE EDUCAÇÃO SUPERIOR
}

\section{PARADIGM SHIFT: CHALLENGE FOR TEACHER EDUCATION}

\section{Rudimar Gomes Bertotti ${ }^{1}$ \\ Gisele Rietow Bertotti ${ }^{2}$}

\begin{abstract}
RESUMO: Em razão do relevante papel que as Instituições de Educação Superior desempenham em uma sociedade, principalmente formando profissionalmente seus cidadãos, é necessário que estas organizações se capacitem para responder com maior agilidade às demandas, deixando para trás paradigmas conservadores e ultrapassados e dando lugar a novos paradigmas que façam com que os professores não só realizem o processo de transmitir o conhecimento, mas que sejam capazes de criar ou aprofundar o próprio conhecimento em suas áreas. Partindo da hipótese de que é possível implantar mudanças na prática pedagógica da educação superior, o objetivo geral do presente artigo é discorrer sobre a questão dos paradigmas conservador e emergente nessa área da educação e refletir acerca das mudanças necessárias na prática pedagógica. Para alcançar o objetivo mencionado utilizou-se a pesquisa bibliográfica, apoiada em livros, revistas e artigos especializados.Como conclusão destaca-se que as IES estão sendo desafiadas pela sociedade, que exige uma nova instituição que produza e dissemine o conhecimento, equipando os alunos com ferramentas para que construam uma sociedade mais justa e solidária. Nesse sentido, procurar novos paradigmas que resgatem a educação superior do comportamento conformista vigente é essencial.
\end{abstract}

PALAVRAS-CHAVE: educação superior, paradigma newtoniano-cartesiano, paradigmaconservador, pensamento sistêmico, paradigma emergente.

ABSTRACT: Due to the significant role that institutions of higher education play in a society, especially professionally forming its citizens, it is necessary to enable these organizations to respond faster to the demands, leaving behind conservative and outdated paradigms and giving rise to new paradigms. The teachers should be able create or deepen

\footnotetext{
${ }^{1}$ Professor da rede municipal de ensino de Curitiba, é licenciado em História e Pedagogia. Mestre em Educação pela Universidade Federal do Paraná (UFPR) e Doutorando em Educação pela Pontifícia Universidade Católica do Paraná (PUC-PR). Grupo de Pesquisa: Grupo História das Instituições Escolares no Brasil (GIEB).

2 Professora da Pontifícia Universidade Católica do Paraná (PUC-PR), é licenciada em Letras e Pedagogia. Mestre e Doutora em Educação pela Pontifícia Universidade Católica do Paraná (PUC-PR).
}

Saberes Pedagógicos, Criciúma, v. 4, nº1, janeiro/abril 2020.- Curso de Pedagogia- UNESC 
their own knowledge in your areas and transmit them. Assuming that if can deploy changes in pedagogical practices of higher education, the general aim of this article is to discuss the question of conservative and emerging paradigms in the area of education and think about the necessary changes in pedagogical practice. To achieve the mentioned objective we used the literature based on books, magazines and articles. In conclusion stands out that IES are being challenged by societal demands for a new institution that produces and disseminates knowledge, equipping students with tools to build a more just and caring society. So is essential search new paradigms to rescue the education of current conformist behavior.

KEY-WORDS: Higher education, Cartesian-Newtonian paradigm, paradigm conservative, systemic thinking, the emerging paradigm.

\section{INTRODUÇÃ̃O}

A educação superior vem sendo objeto de debate e de profundas reformulações no Brasil e no mundo, discutindo "as modificações que se operam nas relações entre a sociedade e o Estado, as inovações na base técnica do trabalho, a necessidade de expansão acelerada da educação superior e a crescente exclusão social" (COUTINHO, 2003, p. 1). Neste contexto, a visão que as Instituições de Educação Superior (IES) têm tentado passar para a sociedade vem se alterando constantemente.

Nos últimos anos do Brasil as IES têm enfrentado problemas desafiadores, num contexto marcado por mudanças como a acirrada competição, a baixa capacidade de resposta às demandas internas e externas, a busca pela excelência da qualidade, a escassez de recursos, a necessidade de maior produtividade e rentabilidade acadêmica, a presença das novas tecnologias educacionais e a avaliação acadêmica e institucional. E em razão do relevante papel que as IES desempenham em uma sociedade, principalmente formando profisisonalmente os cidadãos, é necessário que estas organizações se capacitem para responder com maior agilidade às demandas, deixando para trás paradigmas conservadores e ultrapassados e dando lugar a novos paradigmas que façam com que os professores não só realizem o processo de transmitir o conhecimento, mas que sejam capazes de criar ou aprofundar o próprio conhecimento em suas áreas.

Partindo da hipótese que é possível implantar mudanças na prática pedagógica

Saberes Pedagógicos, Criciúma, v. 4, nº1, janeiro/abril 2020.- Curso de Pedagogia- UNESC 
da educação superior, o objetivo geral do presente artigo é discorrer sobre a questão dos paradigmas conservador e emergente nessa área da educação e refletir acerca das mudanças necessárias na prática pedagógica, retomando o contexto histórico do paradigma conservador como fonte de busca de processos educativos, na tentativa de superar o pensamento newtoniano-cartesiano e ultrapassar a fragmentação do conhecimento em busca de uma transformação social da realidade. As contínuas mudanças sociais e culturais exigem mudanças no processo educacional, principalmente no que diz respeito à prática docente. É necessário que o professor universitário esteja aberto a essas mudanças; esse é o desafio. Para alcançar o objetivo mencionado utilizou-se a pesquisa bibliográfica, apoiada em livros, revistas e artigos especializados.

Como conclusão destaca-se que as IES estão sendo desafiadas pela sociedade que exige uma nova instituição que produza e dissemine o conhecimento, e mais especificamente o conhecimento especializado, equipando os estudantes com ferramentas para que realizem, contribuam e "sejam empregáveis" (DRUCKER, 1999, p. 154) - e pelo Estado - que por meio da Lei de Diretrizes e Bases da Educação Nacional, exige das IES uma orientação voltada para "maior autonomia, descentralização e flexibilidade" (MEYER JR, 2003, p. 175). Nesse sentido, procurar novos paradigmas que resgatem a educação superior de um "comportamento conformista em relação a um status quo vigente" (MEYER JR, 2003, p. 175) é essencial.

\section{O QUE É PARADIGMA}

Paradigma é uma palavra de origem grega (parádeigma) e significa "modelo, representação de um padrão a ser seguido". É um pressuposto filosófico, uma teoria, um conhecimento que origina um estudo posterior; é uma referência inicial, como base de modelo para estudos e pesquisas (CHITTONI, 2009). Segundo o mencionado autor, usualmente o termo "paradigma" tem sido usado para designar um pensamento fechado, imutável, inflexível. Por exemplo, se alguém afirma que uma pessoa, um grupo ou uma comunidade tem dificuldades em "renovar suas crenças", está afirmando que existe uma

Saberes Pedagógicos, Criciúma, v. 4, nº1, janeiro/abril 2020.- Curso de Pedagogia- UNESC 
dificuldade em rever um paradigma.

O físico Thomas Kuhn estudou os movimentos transformadores da ciência e publicou, em 1962, A estrutura das revoluções científicas, onde tratou com profundidade como surge um paradigma. No entendimento de Kuhn são até comuns os momentos em que uma teoria muito bem embasada é completamente abandonada em detrimento de outra. Do mesmo modo, existem teorias que ao longo do tempo vão se modificando tanto que se tornam totalmente diferentes do que eram originalmente. São os movimentos transformadores da ciência, mais conhecidos como paradigmas.

Para Kuhn (apud SANTOS, 2008, p. 1), paradigma é "um modelo de mundo que compreende o conjunto de teorias que buscam explicar os fenômenos estudados"; é "a constelação de crenças, valores e técnicas partilhadas pelos membros de uma comunidade científica. É aquilo que os membros de uma comunidade partilham e, inversamente, uma comunidade consiste em homens que partilham um paradigma" (KUHN, 1991, p. 225). É um esquema de interpretação básico, que compreende supostos teóricos gerais, leis e técnicas que uma comunidade científica adota; é uma realidade aceita que inclui leis, teorias, aplicações e instrumentações.

\begin{abstract}
O que um paradigma faz é estabelecer algumas questões sobre o mundo físico que são então investigadas na tentativa de se encontrar respostas. No entanto, um paradigma parece nunca conseguir responder todas as questões que propõe. A ciência não é um empreendimento de respostas. Quanto mais sabemos sobre determinado fenômeno, mais questões surgem. Isso não é exatamente um problema, ao menos não inicialmente. Esse processo investigativo é o que Kuhn chamou de 'ciência normal', ou seja, o período aonde determinados paradigmas são aceitos e investigados (SANTOS, 2008, p. 1).
\end{abstract}

Porém, quando se tem um grande número de questões que não podem ser resolvidas dentro do paradigma vigente ele acaba atingindo níveis críticos e entrando em um período conhecido por "crise". É nesse período que novos paradigmas tentam responder de maneira mais eficiente as questões que o paradigma aceito não consegue responder. O período de crise é marcado pela divisão da comunidade científica entre o paradigma aceito e o paradigma em ascensão. Eventualmente, o paradigma em ascensão ganha a preferência e substitui o antigo - dá-se a "revolução científica" proposta por

Saberes Pedagógicos, Criciúma, v. 4, nº1, janeiro/abril 2020.- Curso de Pedagogia- UNESC 
Kuhn. Claro que esse é um processo lento, que se estende por um longo período de tempo e gera inúmeras discussões.

Todas as áreas da ciência têm seus paradigmas. O primeiro que norteou a área da educação foi o paradigma conservador, que tem seu fundamento no paradigma newtoniano-cartesiano. O paradigma que se contrapõe a ele é o emergente, fundamentado no pensamento sistêmico.

\title{
3 PARADIGMA NEWTONIANO-CARTESIANO E PENSAMENTO SISTÊMICO
}

\section{O paradigma newtoniano-cartesiano (também conhecido apenas como} paradigma cartesiano) nasceu na Idade Moderna, a partir das idéias de Galileu Galilei, e fundamentou os ditames da ciência durante séculos.

O paradigma cartesiano teve sua origem histórica em Galileu Galilei, que introduziu a descrição matemática da natureza reconhecendo a relevância das propriedades quantificáveis da matéria (forma, tamanho, número, posição e quantidade do movimento). Contaminado por esses estudos, Descartes (15961650) propôs o 'Discurso do Método' com os seguintes pressupostos: jamais acolher alguma coisa como verdade sem evidência concreta; dividir cada um dos conceitos em tantas parcelas quanto possível para resolvê-las; partir da ordem dos conceitos mais simples para os mais complexos para conduzir degrau a degrau o conhecimento; e buscar em toda parte enumerações tão completas e revisões tão gerais, que provocasse a certeza de nada omitir (BEHRENS, 2005, p. 18).

O paradigma cartesiano substituiu os pensamentos aristotélico e cristão, que ditavam as regras da ciência medieval, como afirma Capra (1996, p. 34):

\begin{abstract}
Nos séculos XVI e XVII, a visão de mundo medieval, baseada na filosofia aristotélica e na teologia cristã, mudou radicalmente. A noção de um universo orgânico, vivo e espiritual foi substituída pela noção do mundo como uma máquina, e a máquina do mundo tornou-se a metáfora dominante da era moderna. Essa mudança radical foi realizada pelas novas descobertas em física, astronomia e matemática, conhecidas como Revolução Científica, e associadas aos nomes de Copérnico, Galileu, Descartes, Bacon e Newton.
\end{abstract}

Porém, o pensamento newtoniano-cartesiano não conseguiu êxito em todas as esferas da ciência. Por exemplo, na biologia

Saberes Pedagógicos, Criciúma, v. 4, nº 1, janeiro/abril 2020.- Curso de Pedagogia- UNESC 
o maior sucesso do modelo mecanicista de Descartes foi a sua aplicação na circulação sanguínea, por Willian Harvey. Inspirados pelo sucesso de Harvey, os fisiologistas de sua época tentaram aplicar o modelo mecanicista para descrever outras funções somáticas, tais como a digestão e o metabolismo. No entanto, essas tentativas foram desanimadores malogros, pois os fenômenos que os fisiologistas tentaram explicar envolviam processos químicos que eram desconhecidos na época e não podiam ser descritos em termos mecânicos (CAPRA, 1996, p. 35).

Mas, mesmo com o desenvolvimento da química, ressaltando as descobertas de Antoine Lavoisier (considerado o criador da química moderna), a essência da idéia cartesiana sobreviveu. Por exemplo, os animais eram (e são) encarados como máquinas, apesar de o funcionamento de seus organismos ser muito mais complicado do que mecanismos da relojoaria, pois envolve complexos processos químicos.

Embora o pensamento cartesiano fosse hegemônico em sua época, a partir do final do século XVIII recebeu a primeira forte oposição com o movimento romântico, fato que pode ser claramente percebido nas palavras do poeta William Blanke (um dos exponenciais do romantismo inglês e crítico inveterado das idéias de Newton), como resume em um de seus versos: "Possa Deus nos proteger da visão única e do sono de Newton.

Os pensadores românticos alemães resgataram o pensamento aristotélico, visível nas obras de Goethe e Immanuel Kant. Mas, apesar desta oposição, o pensamento newtoniano-cartesiano fica mais forte na segunda metade do século XIX com o aperfeiçoamento do microscópio, que leva a biologia a grandes avanços e descobertas.

Somente no século XX a ciência percebeu, por meio das reflexões da biologia organísmica e principalmente com as descobertas da física quântica, o desgaste do mecanicismo proposto pelo modelo newtoniano-cartesiano. Como afirma Capra (1996, p. 41),

desde Newton os físicos têm acreditado que todos os fenômenos físicos podiam ser reduzidos às propriedades de partículas, matérias rígidas e sólidas. No entanto, na década de 20, a teoria quântica forçou-os a aceitar o fato de que os objetos materiais sólidos da física clássica se dissolvem, no nível subatômico, em padrões de probabilidade semelhantes a ondas. Além disso, esses padrões

Saberes Pedagógicos, Criciúma, v. 4, nº1, janeiro/abril 2020.- Curso de Pedagogia- UNESC 
não representam probabilidades de coisas, mas sim probabilidades de interconexões. As partículas subatômicas não tem significado, enquanto entidades isoladas, mas podem ser entendidas somente como interconexões, ou correlações, entre vários processos de observação e medida.

Apesar das contribuições da física quântica para superação do paradigma cartesiano, não se pode negar que esse processo de transformação paradigmática foi resultado do choque de várias vertentes da ciência com o paradigma vigente, como a biologia organísmica com o seu novo modo de pensar - o "pensamento sistêmico"; é neste contexto que um novo paradigma científico foi formulado.

O pensamento sistêmico se baseia em uma perspectiva do todo, ou seja, se contrapõe à ênfase dada às partes, propondo a reunião dos fragmentos, a soma das partes. Nesta perspectiva Capra (1996, p. 40) explica:

As idéias anunciadas pelos biólogos organísmicos durante a primeira metade do século ajudaram a dar à luz um novo modo de pensar - o pensamento sistêmico - em termos de conexidade, de relações, de contexto. De acordo com a visão sistêmica, as propriedades essenciais de um organismo, ou sistema vivo, são propriedades do todo, que nenhuma das partes possui. Elas surgem das interações e das relações entre as partes. Essas propriedades são destruídas quando o sistema é dissecado, física ou teoricamente, em elementos isolados. Embora possamos discernir partes individuais em qualquer sistema, essas partes não são isoladas, e a natureza do todo é sempre diferente da mera soma de suas partes.

Portanto, o pensamento sistêmico quebra o determinismo de séculos de pensamento mecanicista, porém sua efetivação não é imediata: é um processo de reintegração das partes que age de forma transformadora na ciência, como propõe Behrens (2005, p. 35):

\begin{abstract}
Essas teorias inovadoras, entre outras, desenvolvidas pelos cientistas e intelectuais desde o início do século XX, provocaram uma grande guinada na ciência, desacreditando verdades tidas como absolutas e inquestionáveis. O desafio e o desequilíbrio impostos à teoria newtoniana-cartesiana levam à proposição de teorias que se complementam, se interpenetram, como uma colcha de retalhos ainda por costurar, mas já influenciam o compartilhamento de conhecimentos e idéias.
\end{abstract}

No novo pensamento sistêmico o cerne da questão é o todo, visualizado através da união das partes, trazendo a idéia de rede, ou seja, o universo do conhecimento como uma teia dinâmica de eventos inter-relacionados. Para Castells (2002, p. 565), Saberes Pedagógicos, Criciúma, v. 4, nº1, janeiro/abril 2020.- Curso de Pedagogia- UNESC 
"redes constituem a nova morfologia social de nossas sociedades, e a difusão da ló gica de redes modifica de forma substancial a operação e os resultados dos processos produtivos e de experiência, de poder e cultura". A sociedade em rede é a sociedade atual em que os homens vivem.

\section{INFLUÊNCIA DO PARADIGMA NEWTONIANO-CARTESIANO NA EDUCAÇÃO SUPERIOR: O PARADIGMA CONSERVADOR}

Para iniciar este item entende-se pertinente a colocação de Behrens (2005, p. 51) a respeito do paradigma conservador da educação: “A educação é proposta como em uma fábrica: o aluno entra numa esteira de produção, é processado e resulta num produto". Esse é o pensamento enraizado na educação superior brasileira, que a mantém sob caráter totalitário, porém, justificável sob o ponto de vista paradigmático, como pressupõe Santos (2000, p. 61):

\footnotetext{
sendo um modelo global, a racionalidade científica é também um modelo totalitário, na medida em que nega o caráter racional a todas as formas de conhecimento que não se pautarem pelos seus princípios epistemológicos e pela suas regras metodológicas. É esta a sua característica fundamental.
}

Nesta perspectiva fica clara a influência do paradigma newtoniano-cartesiano, que vê o ser humano como uma máquina que apenas reage a estímulos externos e que não possui emoção, devendo ser tratado apenas pela razão. Esse também é o entendimento passado para a educação, que "alicerçada nos pressupostos do pensamento newtonianocartesiano" apresenta "um pensamento racional, fragmentado e reducionista" (BEHRENS, 2005, p. 19).

No paradigma cartesiano para se adquirir o conhecimento é necessário medir, quantificar, dividir e repetir, ou seja, o conhecimento baseia-se na idéia de ordem, de caráter estável e funcional, que utiliza o método empírico-racional fundamentado no pensamento reducionista, simplificado. A visão do universo que prevalece é a do "mundomáquina que deu origem ao mecanicismo e à possibilidade de trabalhar o raciocínio pela

Saberes Pedagógicos, Criciúma, v. 4, nº1, janeiro/abril 2020.- Curso de Pedagogia- UNESC 
indução e dedução" (BEHRENS, 2005, p. 21). O homem é separado da emoção, da natureza e da religiosidade.

Nesse contexto pode-se ver claramente a influência do paradigma newtonianocartesiano na educação superior com a fragmentação das disciplinas, onde o professor aprendia somente dentro de uma única linha de um grande sistema mecânico para ensinar aos alunos. Em vista disso foram criados cursos fragmentados que dividiram o conhecimento em áreas: humanas, exatas, biológicas e jurídicas. De acordo com Behrens (1999, p. 384), a influência do paradigma cartesiano

\begin{abstract}
repartiu o conhecimento em áreas, as áreas em cursos, os cursos em disciplinas, as disciplinas em especificidades. A repartição foi tão contundente que levou os professores a realizarem um trabalho docente completamente isolados em suas salas de aula. Outro fator relevante de influência deste paradigma na ação docente é a busca da reprodução do conhecimento. Caracterizada pela fragmentação, a prática pedagógica propõe ações mecânicas aos alunos, provocando um ensino assentado no escute, leia, decore e repita. Estas quatro ações têm sido propostas como metodologia no ensino universitário por um longo período na história da educação.
\end{abstract}

No pensamento cartesiano-newtoniano o professor é quem domina o conhecimento, deixando o aluno refém dele; tanto que o aluno é induzido a não ter criticidade nenhuma. Apesar de o professor "não ter culpa" de sua prática, pois foi assim que ele aprendeu quando era aluno, quando ele passa para a prática educacional repete a forma como aprendeu, entendendo-a como certa.

O paradigma conservador ensina a não questionar e aceitar passivamente a autoridade. Moraes (1998, p. 50) ressalta que o professor conservador limita os alunos "ao espaço reduzido de suas carteiras, imobilizados em seus movimentos, silenciados em suas falas, impedidos de pensar. Reduzidos em sua criatividade e em suas possibilidades de expressão", os alunos também ficam limitados na sociabilidade, presos à mente racional, impossibilitados "de experimentar novos vôos e de conquistar novos espaços".

$\mathrm{Na}$ abordagem conservadora da educação o professor é o responsável pela transmissão do conhecimento e enxerga o aluno como uma tábula rasa. Em termos metodológicos, as aulas são expositivas e os alunos fazem provas com questões que envolvem a reprodução dos conteúdos apenas para tirar boas notas.

Saberes Pedagógicos, Criciúma, v. 4, nº1, janeiro/abril 2020.- Curso de Pedagogia- UNESC 


\section{SABERES PEDAGÓGICOS}

Revista do Curso de Graduaçāo de Pedagogia - Unesc

ISSN 2526-4559

A reprodução do conhecimento, a repetição dos conteúdos e a visão mecanicista da dinâmica educacional estão presentes nas tendências pedagógicas de cunho liberal, que inclui a pedagogia tradicional (paradigma conservador), a pedagogia renovada (paradigma escolanovista) e o tecnicismo educacional (paradigma tecnicista).

A pedagogia tradicional apresenta uma forte valorização de determinadas disciplinas acadêmicas, "uma vez que todos os fenômenos complexos, para serem compreendidos, necessitam serem reduzidos às suas partes constituintes" (MORAES, 1998, p. 41). Traz ainda a fragmentação do todo disciplinar e a separação, na aprendizagem, entre razão e emoção, corpo e mente, ciência e ética. A didática é uma disciplina normativa, um conjunto de princípios e regras que regulam o ensino. A atividade de ensinar é centrada no professor que expõe e interpreta a matéria. A relação entre professor e aluno é distante e verticalizada, tendo o professor uma postura autoritária, severa, rigorosa e objetiva; o professor possui o poder decisório e apenas informa e conduz o aluno baseado em sua ideologia tradicional. $\mathrm{O}$ aluno apresenta-se como um ser passivo e receptivo, que aprende por meio da reprodução do conhecimento, sem espaço para possibilidade de produção, ou seja, o aluno é apenas ouvinte e repetidor do conhecimento lecionado. Sua função no processo educativo é preferencialmente realizar tarefas, sem questionar o objetivo proposto. E a metodologia na abordagem tradicional fundamenta-se em princípios como repetição e memorização. O intuito não está em fazer o aluno aprender, mas decorar os conteúdos apresentados. Por isso o método é baseado em aulas expositivas com conteúdo pronto, onde se reproduz os mesmos, tornando o aluno um simples ouvinte com o objetivo de fixar o conteúdo na memória.

A pedagogia escolanovista já permite a maior participação do aluno, com a devida responsabilização no processo ensino-aprendizagem, mas isto não impede a imposição de valores individualistas aos alunos. O professor se apresenta mais humano, disposto a auxiliar no desenvolvimento livre e espontâneo do aluno, mantendo um relacionamento positivo com o mesmo e agindo como um facilitador da aprendizagem. A metodologia é focada no indivíduo e nos trabalhos e experiências em grupo, sendo que o professor deve levar em conta as exigências psicológicas, as características pertinentes a

Saberes Pedagógicos, Criciúma, v. 4, nº 1, janeiro/abril 2020.- Curso de Pedagogia- UNESC 
cada educando e a contribuição para o desenvolvimento das capacidades e habilidades intelectuais do aluno.

O tecnicismo educacional defende o processo de aprendizagem como uma espécie de controle científico da educação, preparando o aluno para o processo produtivo capitalista e as regras de eficiência e resultados no mundo corporativo. A forte influência cartesiana leva o professor ao determinismo e ao racionalismo, e com essa exigência o professor passa a aplicar a técnica, em busca de performance. O professor atua como um engenheiro comportamental, o responsável em propagar a idéia de que basta o aluno, num processo controlado, "aprender a fazer". O aluno apresenta-se como um espectador frente à realidade objetiva. A incessante busca de desempenho torna o aluno condicionado, responsivo e acrítico. A metodologia fundamenta-se em conjuntos de atividades que facilitam a aquisição de um ou vários objetivos de ensino. Esta abordagem remete ao paradigma conservador, trazendo de volta a reprodução do conhecimento, a memorização dos conteúdos, a valorização de aulas expositivas e os exercícios repetitivos.

\section{A INFLUÊNCIA DO PENSAMENTO SISTÊMICO: O PARADIGMA EMERGENTE}

Como foi abordado, o pensamento sistêmico se baseia em uma perspectiva que envolve o todo, ou seja, se contrapõe à ênfase cartesiana da fragmentação, propondo a soma das partes, que se interrelacionam. Tal pensamento reconhece que todos os seres são interdependentes, e que "nossas vidas estão entrelaçadas com o mundo atual, dependem de nossa atuação e nosso contexto, em nossa realidade, que será revelada mediante uma construção ativa em que o indivíduo participe" (MORAES, 1998, p. 22). Todo indivíduo é produtor de conhecimento.

No pensamento sistêmico aprender não significa ser capaz de reproduzir comportamentos ou memorizar conteúdos pré-fixados. Aprender, no sentido sistêmico e abrangente do termo, significa ser capaz de transformar-se, de modo a modificar a própria estrutura de comportamento, tornando-a mais eficaz no sentido de perseguir os valores

Saberes Pedagógicos, Criciúma, v. 4, nº1, janeiro/abril 2020.- Curso de Pedagogia- UNESC 
essenciais da própria pessoa, grupo social ou comunidade.

A partir do pensamento sistêmico surgem novas formas de pensar a educação, surgindo, por consequiência, um novo paradigma, conhecido como paradigma emergente, cuja grande inovação é que o aluno passa a ser visto como sujeito do processo, interagindo com o conhecimento e participando da construção do mesmo.

Completo é o entendimento de Behrens (1999, p. 387) com relação ao paradigma emergente:

\begin{abstract}
Na liberdade que cada professor e pesquisador tem para dimensionar o novo paradigma, acredita-se que há necessidade de atender às características de rede, de teia, de sistema, de produção do conhecimento, de trabalho coletivo e compartilhado, de interconexão, de inter-relacionamento, de reaproximação das partes do todo. E ainda, de exigência de diálogo, de atitude crítica, criativa e transformadora. Nesse contexto, para propor um paradigma emergente na prática pedagógica, que atenda a esses pressupostos inovadores citados, não há uma única abordagem a ser contemplada. Mas a proposta, nesse momento histórico, aponta para a construção de uma aliança, de uma teia, de um grande encontro, dos pressupostos e referenciais de três abordagens que possam atender às exigências da sociedade do conhecimento: abordagem progressista, ensino com pesquisa e visão sistêmica.
\end{abstract}

Segundo Behrens (1999, p. 397), a abordagem progressista

tem como pressuposto central a transformação social. Instiga o diálogo e a discussão coletiva como forças propulsoras de uma aprendizagem significativa e contempla os trabalhos coletivos, as parcerias e a participação crítica e reflexiva dos alunos e dos professores. Os docentes que optam por uma abordagem progressista, como intelectuais transformadores, promovem processos de mudança manifestando-se contra as injustiças sociais, as atitudes antiéticas, as injustiças políticas e econômicas. Num processo dialógico, instigam seus alunos a buscar soluções que permitam aos homens uma melhor qualidade de vida.

O professor progressista impõe autoridade por meio da competência, contextualiza o conteúdo e busca o diálogo, consciente de ser, juntamente com o aluno, sujeito do processo. Age como um norteador, direcionando e conduzindo os alunos ao caminho do saber. É um ser crítico, inclusive de sua própria prática pedagógica, que une teoria e ação. A metodologia na abordagem progressista está embasada na problemática e no diálogo. Todas as ações dentro do processo educativo passam por uma profunda reflexão. As produções são críticas e tendem a corresponder a conteúdos de real interesse Saberes Pedagógicos, Criciúma, v. 4, nº1, janeiro/abril 2020.- Curso de Pedagogia- UNESC 
e necessidades do grupo. No pensamento de Rosenau e Trevisan (2007, p. 10), a metodologia progressista

empreende processos de autonomia e liberdade, alicerçada pela contextualidade e problematização; contempla a formação do indivíduo como ser histórico a partir do princípio dialético da ação-reflexão-ação; e, também, privilegia a aquisição do saber vinculado às realidades sociais.

Deve, ainda, instigar a capacidade crítica dos alunos, como defende Freire (1996, p. 28):

o educador democrático não pode negar-se o dever de, na sua prática docente, reforçar a capacidade crítica do educando, sua curiosidade, sua insubmissão. Uma de suas tarefas primordiais é trabalhar com os educandos a rigorosidade metódica com que devem se "aproximar" dos objetos cognoscíveis.

A abordagem holística busca dar uma nova visão à educação, trazendo para esse universo referências que jamais tinham sido citadas e incorporadas pelos educadores, tais como a visão do homem com um ser do universo. Nessa "visão holística" o homem passa a ser visto em "corpo, intelecto, sentimento e espírito" (CREMA, 1995, p. 50), desenvolvendo-se em sua dimensão física e psíquica, desenvolvendo suas potencialidades. E passa a ver o todo de forma sistêmica, e não sistemática, quebrando o modelo e construindo uma rede (ou teia) para a educação. A visão holística faz o homem pensar sobre uma nova possibilidade de formação educacional e conhecimento. Behrens (2005, p. 63-64) afirma que "o grande desafio da visão holística é a superação do saber fragmentado, que foi dividido na escola em disciplinas isoladas".

Segundo Behrens, Moran e Masetto (2000, p. 92),

a visão holística busca a perspectiva interdisciplinar, superando a fragmentação, a divisão, a compartimentalização do conhecimento. O processo educativo numa abordagem holística implica aprender a conhecer, aprender a fazer, aprender a conviver, aprender a aprender, aprender a ser. Nesse contexto de múltiplas aprendizagens, leva em consideração processos de superação de dualidades propostas no paradigma cartesiano, entre razão-emoção, corpo-alma, objetivosubjetivo e sujeito-objeto, entre outras.

Saberes Pedagógicos, Criciúma, v. 4, nº 1, janeiro/abril 2020.- Curso de Pedagogia- UNESC 
$\mathrm{Na}$ educação superior de abordagem holística as disciplinas são organizadas em um todo integrado e o aluno também passa a se organizar para conhecer e se relacionar com esse todo. "O aluno precisa ser considerado em suas inteligências múltiplas e pelos dois lados do cérebro (BEHRENS, 1999, p. 72). Isso faz com que o aluno passe a ser reflexivo, produtivo e crítico da prática pedagógica, vivenciando um crescimento gradativo e avaliativo.Ele é um ser único e valioso, porém consciente de sua conexão com o todo e com as relações complexas que o envolvem. O professor trabalha em parceria com os alunos, na direção de um ensino de qualidade, buscando uma prática pedagógica transformadora. Na superação da fragmentação o professor necessita fazer uma conexão entre teoria e prática em seus métodos pedagógicos, para que os alunos possam enxergar o todo, bem como os processos e relações que o permeiam. Pode-se até dizer que, na abordagem holística o professor é um amigo, parceiro e colaborador do aluno, discutindo sentimentos e emoções, buscando caminhos alternativos que embasem uma ação docente relevante, mas principalmente agindo para a superação do paradigma cartesiano no que concerne à produção do conhecimento e não mais a mera reprodução. Indo mais além, Behrens (2005, p. 63) evidencia o trabalho do professor holístico que procura desenvolver o lado direito do cérebro do aluno:

\begin{abstract}
Os professores, de maneira geral, têm provocado nos estudantes somente o uso do cérebro do lado esquerdo. Este lado domina a racionalidade cientifica e a memorização, que pode incluir novas informações no esquema existente das coisas, mas não instiga novas idéias. No entanto, o cérebro do lado direito, pouco contemplado na prática pedagógica do professor, desenvolve a intuição, a sensibilidade, a criatividade, a estética, o sentimento, e estabelece conexão, permitindo ver o contexto e avaliar o significado.
\end{abstract}

A abordagem ensino com pesquisa apresenta a parceria entre aluno e professor no processo pedagógico, gerando a busca da produção do conhecimento e a superação da cópia e da repetição (DEMO, 1996). Tem seu foco no espírito investigativo do aluno e na sua capacidade produtiva para a construção de textos próprios, fruto de sua criatividade e raciocínio lógico, pautado intrinsecamente com a pesquisa. O professor é o orquestrador da construção do conhecimento e vanguardista do desenvolvimento do aluno, contribuindo

Saberes Pedagógicos, Criciúma, v. 4, nº1, janeiro/abril 2020.- Curso de Pedagogia- UNESC 
para a produção da ciência e da tecnologia com criatividade, criticidade e espírito transformador. Ambos, professor e aluno, são sujeitos do processo educacional. A metodologia dessa abordagem é fundamentada na pesquisa, porém, não na pesquisa em que uma grande maioria de alunos se habituou, ou seja, compilar conteúdos de vários autores sem um propósito real de investigação, apenas para cumprir as exigências. Pelo contrário, o ensino com pesquisa contempla outra dimensão: o enfoque deve ser na produção de um conhecimento crítico e reflexivo, que dê autonomia ao aluno e o faça refletir e problematizar o conhecimento.

Behrens (1999, p. 387) conclui que o ponto de encontro das abordagens progressista, holística e ensino com pesquisa é

a superação da reprodução e a busca da produção do conhecimento. Na realidade, é uma produção do conhecimento que permite aos homens serem éticos, autônomos, reflexivos, críticos e transformadores; que, ao inovar os profissionais e, em especial, os professores, preocupem-se em oferecer uma melhor qualidade de vida para os homens, provocando, nesse processo, uma reflexão de que se vive num mundo global, portanto, são responsáveis pela construção de uma sociedade mais justa e igualitária.

A proposta do pensamento sistêmico para o professor de educação superior é que sua ação docente alie as abordagens progressista, holística e ensino com pesquisa de tal modo que, como uma teia, se interconectem e subsidiem pressupostos para uma prática pedagógica num paradigma emergente. O paradigma do século XXI é o da sociedade do conhecimento e não mais a proposição mecanicista e reducionista que leva à fragmentação.

A revolução científica e tecnológica que o mundo contemporâneo tem vivenciado e cuja base está assentada num permanente processo de aprender a aprender tem que penetrar também na educação. Não existe mais lugar para a prática pedagógica conservadora, repetitiva e acrítica. Essa prática precisa desafiar os alunos a buscarem uma formação humana, crítica e competente, que envolva: a abordagem progressista, cujo pressuposto central é a transformação social; o ensino com pesquisa, que provoca a superação da reprodução do conhecimento para a produção do conhecimento; e a visão

Saberes Pedagógicos, Criciúma, v. 4, nº1, janeiro/abril 2020.- Curso de Pedagogia- UNESC 


\section{SABERES PEDAGÓGICOS}

Revista do Curso de Graduaçāo de Pedagogia - Unesc

ISSN $2526-4559$

holística, que tem como objetivo maior resgatar o homem em sua totalidade.

\section{CONCLUSÃO}

O paradigma emergente traz nova luz à educação, dando oportunidade ao professor de educação superior para uma prática pedagógica que incite a sustentabilidade e a justiça social, valores dos quais o mundo está tão carente.

A superação do paradigma newtoniano-cartesiano se apresenta como uma necessidade no atual momento histórico. Afinal, vive-se em uma sociedade de consumo com graves desequilíbrios sociais, onde a educação superior é para poucos e onde os indivíduos não se enxergam como fazendo parte do todo: não percebem que suas atitudes podem interferir na biosfera e na qualidade de vida das próximas gerações.

Nesse contexto o papel do professor torna-se ainda mais importante, no sentido de ser o agente transformador, o propagador da ruptura paradigmática em espaços em que ela ainda não aconteceu.

As novas abordagens pedagógicas se fazem presentes para transformar a práxis docente. Porém, o que ainda se vê na educação superior (e também nas que a antecedem) são sólidas permanências no paradigma cartesiano. Tal forma de pensar e agir ainda espalha a fragmentação, as distinções, as separações, enfim, a ruptura do todo, dando ênfase às partes e, por conseqüência, levando os alunos a verem o mundo como que feito de pedaços desconectados. Ainda: os alunos internalizam o que é repassado, sem a devida reflexão e questionamento, aceitando aquele conhecimento como verdade absoluta e acabada. O professor é o detentor do saber inquestionável. A metodologia empregada contempla a memorização mecânica de conteúdos, levando a um aprendizado sem significado ou sentido.

A educação superior precisa de professores que empreguem práticas pedagógicas que contemplem o paradigma emergente, em todas as suas abordagens: progressista, holística e ensino com pesquisa, reduzindo as aulas teóricas, enfatizando a pesquisa e a construção de textos próprios, estimulando o debate e a discussão dentro de

Saberes Pedagógicos, Criciúma, v. 4, nº 1, janeiro/abril 2020.- Curso de Pedagogia- UNESC 


\section{SABERES PEDAGÓGICOS}

Revista do Curso de Graduaçāo de Pedagogia - Unesc

ISSN 2526-4559
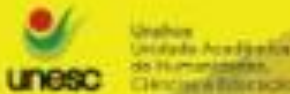

sala de aula, com reflexões sobre o conhecimento em questão.

O professor de educação superior é o orquestrador do processo educacional. E este papel vai além das fronteiras das salas de aula, concorrendo para a construção de um mundo mais humano, sensível, justo e ético, para a atual e as futuras gerações.

\section{REFERÊNCIAS}

BEHRENS, M. A. O paradigma emergente e a prática pedagógica. Curitiba: Vozes, 2005.

BEHRENS, M. A. A prática pedagógica e o desafio do paradigma emergente. Revista Brasileira de Estudos Pedagógicos. Brasília, v. 80, n. 196, p. 383-403, set-dez./1999. Disponível em: http://www.rbep.inep.gov.br/index.php/RBEP/article/view/167/166. Acesso em: 18 mar. 2010.

BEHRENS, M. A.; MORAN, J. M.; MASETTO, M. T. Novas tecnologias e mediação pedagógica. Campinas: Papirus, 2000.

CAPRA, F. A teia da vida: uma nova compreensão científica dos sistemas vivos. São Paulo: Cultrix, 1996.

CASTELlS, M. A. A sociedade em rede. 6. ed. São Paulo: Paz e Terra, 2002.

CHITTONI, R. O que é paradigma. jun/2009. Disponível em: http://www.aglo.com.br/blog/?p=680. Acesso em: 15 mar. 2010.

COUTINHO, R. Q. Sugestões do ForGRAD para o aprimoramento do SINAES. Encontro Nacional de Avaliação. Fórum Nacional de Pró-Reitores de Graduação das Universidades Brasileiras. Brasília: UnB, Out/2003. Disponível em: http://www.anfopepe.hpg.ig.com.br/boletim11/sinaes.htm. Acesso em: 20 mar. 2010.

CREMA, R. Uma visão holística da educação. In: CARDOSO, Clodoaldo. A canção da inteireza - uma visão holística da educação. São Paulo: Summus, 1995.

DEMO, P. Educar pela pesquisa. Campinas: Autores Associados, 1996.

DRUCKER, P. F. Sociedade pós-capitalista. 7. ed. São Paulo: Pioneira, 1999.

FREIRE, P. Pedagogia da autonomia - saberes necessários à prática educativa. São Paulo: Paz e Terra, 1996.

Saberes Pedagógicos, Criciúma, v. 4, nº 1, janeiro/abril 2020.- Curso de Pedagogia- UNESC 
KUHN, T. S. A estrutura das revoluções científicas. São Paulo: Perspectiva, 1991.

MEYER JR., V. Novo contexto e as habilidades do administrador universitário. In: MEYER JR, V.; MURPHY, P. (org). Dinossauros, gazelas \& tigres: novas abordagens da administração universitária. Florianópolis: Insular, 2003.

MEYER JR, V. Planejamento estratégico: uma renovação na gestão das instituições universitárias. Seminário Administração Universitária Rumo ao Ano 2000. Florianópolis, agosto/1991.

MORAES, M. C. O paradigma educacional emergente. Campinas: Papirus, 1998.

ROSENAU, L. dos S.; TREVISAN, T. S. Prática docente na universidade: fundamentada em paradigmas conservadores ou inovadores? Revista Intersaberes. Ano 2, n. 4, jul.dez./2007. Disponível em: http://intersaberes.grupouninter.com.br/4/arquivos/05.pdf. Acesso em: 14 mar. 2010.

SANTOS, B. S. A crítica da razão indolente - contra o desperdício da experiência. São Paulo: Cortez, 2000.

SANTOS, T. H. Os 22 paradigmas de Thomas Kuhn. mar.-abr./2008. Disponível em: http://www.eca.usp.br/njr/voxscientiae/thiago_santos_43.htm. Acesso em: 18 mar. 2010. 